\title{
Intravenous Perfusor of Nicardipine to Treat Severe Pre-Esclampsia at Vietnam
}

\author{
Huynh Nguyen Khanh Trang ${ }^{1,2}$ and Hoang Thi Diem Tuyet $^{1 *}$ \\ ${ }^{1}$ Hung Vuong Hospital, Vietnam \\ ${ }^{2}$ University of Medicine Pham Ngoc Thach
}

Submission: May 01, 2019 ; Published: May 08, 2019

*Corresponding author: Hoang Thi Diem Tuyet, Hung Vuong Hospital, Vietnam

\begin{abstract}
Summary
Objectives: Pre-eclampsia-eclampsia is still one of the leading causes of maternal and neonatal mortality in the world. Treatment of severe pre-eclampsia is essentially terminate the pregnancy. However, termination of pregnancy at the right time, especially when gestational age less than 34 weeks, it takes time for corticosteroids to stimulate fetal lung maturation. Antihypertensive drug treatment in severe pre-eclampsia is still different choices, including nicardipne used intravenously as the first choice.

Method: longitudinal study of prospective living 323 cases of singleton pregnancies, gestational age from 30 weeks to 34 weeks, no malformation, was diagnosed with severe preeclampsia at BP $\geq 160 / 110 \mathrm{mmHg}$, in the period from 01/01/2018 to 31/12/2018 at Hung Vuong hospital. Antihypertensive treatment with intravenous nicardipine started with $2.5 \mathrm{mg} / \mathrm{hour}$, increasing the dose of $1.25 \mathrm{mg}$ per $15 \mathrm{minutes}$ (maximum $<15 \mathrm{mg} /$ hour). Track with mornitor in 2 hours. Results: BP starts off after 30 minutes of infusion with good response (69.7\%), good (18.6\%), moderate (7.4\%) and poor response (4.3\% ). BP remained stable in the range of 120/70 and below 140/90 mmHg after 48 hours up to $96.7 \%$.
\end{abstract}

Adverse effects: Tachycardia (9,3\%), Chest tightness (0,3\%), phlebitis at infusion site (4,3\%), basic fetal heart rate increase $(8,0 \%)$.

Conclusion: The intravenous Nicardipne is effective control of blood pressure, the ability to maintain stable blood pressure and safety of antihypertensive treatment in cases of severe pre-eclampsia.

Keywords: Pre-eclampsia-eclampsia; Longitudinal study of prospective; Nicardipine

\section{Introduction}

High blood pressure due to pregnancy or pre-eclampsia is a common disease that accounts for a change of 5 to $10 \%$ of all pregnancies, which can lead to complications that can be fatal to pregnant women and their babies. such as acute pulmonary edema, HELLP syndrome, or eclampsia. Therefore, high blood pressure during pregnancy is still a global problem [1-8]. Epidemiologically, preeclampsia is commonly reported in women younger than 20 years of age or older than 40 years of age, so the incidence of changes is very wide depending on the age, characteristics of each studied population, races, and family character [6].

Hypertension in pregnancy affects mothers and babies with varying degrees. With multi-organ effects, the pathophysiological mechanism recognizes vasoconstriction with many evidence:

a) in normal pregnancy there is a lot of intrusion of cultured cells in the sheath, leading to the region of the arterioles of the arteries followed by the muscular uterine system decreases, the effect is lower blood impedance irrigating each other with uterine blood. This is not in preeclampsia.

b) Increased platelets activated with increased consumption in blood vessels in preeclampsia. Endothelial fibroblasts increased while antithrombin III and $\alpha 2$-antiplasmin decreased, reflecting the endothelial damage. Low antithrombin III leads to microvascular embolism of the vessels, thereby promoting more vasospasm.

c) prostacyclin (PGI2) and thromboxane (TXA2) increased during pregnancy in a balanced manner. The function of PGI2 promotes vasodilation and reduces platelet aggregation. TXA2 predominates in vasoconstriction and platelet aggregation. In pre-eclampsia, change the balance to prioritize TXA2 resulting in vasoconstriction. 
d) Nitric oxide, a strong vasodilator, decreases in preeclampsia which contributes to vasospasm.

e) Lipid peroxide: Free oxygen radical stimulates the formation of oxygen-rich fats leading to endothelial cell damage. These lesions react on intravascular production of Nitric Oxide and disrupt the balance between Prostaglandins.

Free oxygen radicals also appear macrophages containing vascular fat deposits, activating scattered intravascular coagulation (causing thrombocytopenia), increasing capillary permeability (causing edema and protein -products). This may temporarily explain the occurrence of the disease after the 20th week of pregnancy with the usual manifestation of hypertension, proteinuria and edema [2]. Although there is no prevention, early detection to give a timely preparation for mother and fetus. Pregnancy termination at the appropriate time showed reduced morbidity and mortality $[2,6,9]$.

Severe pre-eclampsia treatment is based on the basic principle: preventing seizures with Magnesium sulfate and taking appropriate antihypertensive drugs. After stabilizing blood pressure, it is necessary to assess the likelihood of termination of pregnancy by considering the viability of the fetus (a plan to support respiratory failure due to surfactant deficiency when the fetus is less than 34 weeks gestation ) [2,9].

The use of Magnesium sulfate currently has a uniform regimen in countries, the role and effectiveness of Magnesium sulfate is clear. Antihypertensive drugs need a lot of discussion, but basically based on the following principles: the drug must help improve the condition of pregnant women and their babies, potentially helping pregnant blood pressure to be lower than or equal to $140 / 90 \mathrm{mmHg}$, there is no or little side effects with the liver and kidneys of women, does not cause adverse effects on the fetus. Common groups of drugs used in preeclampsia or eclampsia: central sympathetic inhibition, direct vasodilation, calcium channel blockers, adrenergic inhibition. In Vietnam, previously the preferred regimen in the selection of antihypertensive in severe pre-eclampsia was hydralazine, using intravenous route. This is also the choice of many regimens in the world $[2,6,9]$. Recently, some studies show that another option, intravenous nicardipine is also effective and safe for pregnant women and fetuses in severe pre-eclampsia [3-5]. Therefore, we conducted a study on the efficacy and safety of intravenous nicardipine to control hypertension in severe pre-eclampsia with the following objectives.

\section{Objectives of the Study}

a) Determine the rate of blood pressure in severe preeclampsia that responds well to Nicardipine intravenous pumps.

b) Determine adverse effects on pregnant women (rapid blood vessels, lower blood pressure, dyspnea, flushing, tremor, intravenous phlebitis) and changes in fetal heart on cardio-tocography.

\section{Subjects and Methods}

\section{Research design is longitudinal descriptive study}

Samples selected by sequential methods, all pregnant women selected for the study are the single pregnancy cases, gestational ages of 30 weeks - 34 weeks, determined during the antenatal examination are not malformed, diagnosed Severe pre-eclampsia with blood pressure at admission $\geq 160 / 110 \mathrm{mmHg}$ (measured at least twice a 15-minute rest), urine protein from 5 grams $/ 24$ hours, may have edema or maternal vessels less than 120 times per minute, no complications such as pulmonary edema, HELLP syndrome, eclampsia. Hospitalized at Hung Vuong Hospital during the period from January 1, 2018 to December 31,2018.

\section{Sample size}

$\mathrm{n}=(1-\mathrm{P}) \mathrm{P} / \mathrm{d} 2$ with $95 \%$ confidence level, $=1.96$. Select $\mathrm{P}=70 \%$., $\mathrm{D}=0.05$. Calculate $\mathrm{n}$ at least 323 .

\section{The standard of treatment is good}

the following pregnant blood pressure for the drug is 30 45 minutes to reach $120 / 70 \mathrm{mmHg}$ to $140 / 90 \mathrm{mmHg}$. Meets pretty well when I need 60-90 minutes to reach my target blood pressure. The average response to target blood pressure after 120 minutes and failure when blood pressure does not decrease after 120 minutes treatment.

\section{Exclusion criteria}

previous eclampsia, a clear indication of termination of pregnancy. Heart failure, a history of hypersensitivity to Nicardipine and ECG signs of coronary artery disease, arrhythmia. Nicardipine, $10 \mathrm{ml}$ injection tube with a concentration of $10 \mathrm{mg}$.

\section{Procedure}

The subjects met the sampling criteria, were intravenously injected with an electric pump with a solution consisting of a Nicardipine $10 \mathrm{mg}$ tube $/ 10 \mathrm{ml}$ of $10 \mathrm{ml}$ glucose $5 \%$ (equivalent to $0.5 \mathrm{mg} / \mathrm{ml}$ ). Start $5 \mathrm{ml} /$ hour (equivalent to $2.5 \mathrm{mg} /$ hour). Increases $2.5 \mathrm{ml} /$ hour every 10 minutes (equivalent to $1.25 \mathrm{mg} /$ hour) until the target BP level is reached, usually within $120 / 70 \mathrm{mmHg}$ $140 / 90 \mathrm{mmHg}$. Do not exceed $30 \mathrm{ml} /$ hour (equivalent to $15 \mathrm{mg} /$ hour).

\section{Maintain}

when achieving the desired blood pressure level until necessary assessment of the status of the pregnant woman and the fetus. Monitor blood pressure continuously with a monitor that measures blood pressure every 15 minutes for 120 minutes. Evaluate maintainability up to 48 hours. The fetal heart and uterine contractions are monitored with the obstetric monitor. Results are processed with SPSS 10.0 software.

\section{Results}

Tables 1-3 and Figure 1. 


\section{Journal of Gynecology and Women's Health}

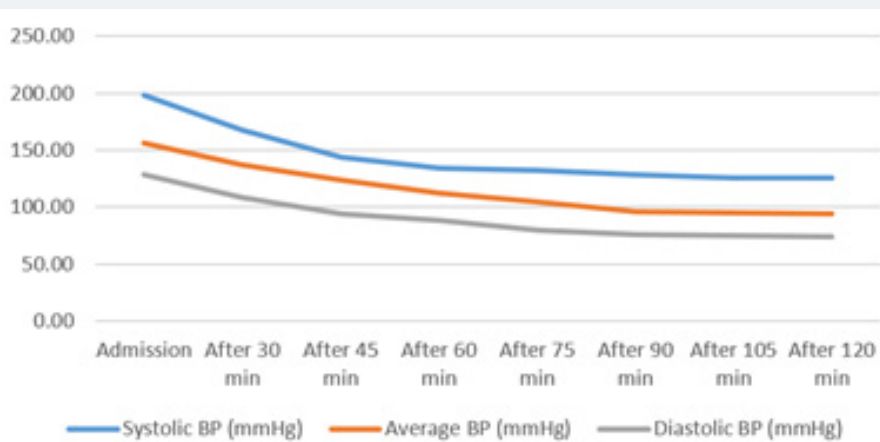

Figure 1: Blood pleasure change with time period of nicardipine usage ( $y . m m h, x:$ minutes).

Table 1: Participant characteristics.

\begin{tabular}{|c|c|c|}
\hline Characteristics & Epidermiology & N (\%) \\
\hline \multirow[t]{3}{*}{ Age } & $<20$ & $128(39,6)$ \\
\hline & $20-39$ & $134(41,5)$ \\
\hline & $\geq 40$ & $61(18,9)$ \\
\hline \multirow[t]{2}{*}{ Living } & Urban & $225(69,7)$ \\
\hline & Rural & $98(30,3)$ \\
\hline \multirow[t]{5}{*}{ Literacy } & Illiteracy & $11(3,4)$ \\
\hline & Primary school & $33(10,2)$ \\
\hline & High school & $169(52,3)$ \\
\hline & College & $74(22,9)$ \\
\hline & Post graduated & $36(11,2)$ \\
\hline \multirow[t]{4}{*}{ Nghề } & Jobholder & $144(46,5)$ \\
\hline & Sellor & $62(19,2)$ \\
\hline & House keeper & $82(25,4)$ \\
\hline & Other & $35(10,9)$ \\
\hline \multirow[t]{3}{*}{ Income } & Low & $75(23,2)$ \\
\hline & Enough & $180(55,7)$ \\
\hline & High & $68(21,1)$ \\
\hline Number & 0 & $246(76,2)$ \\
\hline \multirow[t]{2}{*}{ of children } & 2-Jan & $71(21,9)$ \\
\hline & $\geq 3$ & $6(1,9)$ \\
\hline Gestation age & $30-<31$ & $57(17,6)$ \\
\hline \multirow[t]{3}{*}{ (week) } & $31-<32$ & $66(20,4)$ \\
\hline & $32-<33$ & $89(27,6)$ \\
\hline & $33-34$ & $111(34,4)$ \\
\hline Weight gain & $<10$ (kgs) & $98(30,3)$ \\
\hline \multirow[t]{2}{*}{ (at administration) } & $10-15$ & $92(28,5)$ \\
\hline & $>15$ & $133(41,2)$ \\
\hline \multirow[t]{2}{*}{ Prenatal care } & Enough & $242(74,9)$ \\
\hline & Not enough & $81(25,1)$ \\
\hline Place for & HV hospital & $136(42,1)$ \\
\hline prenatal care & Other & $187(57,9)$ \\
\hline
\end{tabular}

Table 2: Response levels of treatment.

\begin{tabular}{|c|c|}
\hline Response level & N (\%) \\
\hline Very good & $225(69,7)$ \\
\hline Good & $60(18,6)$ \\
\hline Average & $24(7,4)$ \\
\hline Unsuccessful & $14(4,3)$ \\
\hline Total & $323(100)$ \\
\hline
\end{tabular}

Table 3: Side Effects.

\begin{tabular}{|c|c|}
\hline Symtoms & N (\%) \\
\hline Mother pulse $>120 /$ minute & $30(9,3)$ \\
\hline Chest tightness & $3(0,9)$ \\
\hline Phlebitis at infusion site & $14(4,3)$ \\
\hline Basic fetal heart rate $>160-<180$ lần/phút & $26(8,0)$ \\
\hline
\end{tabular}

\section{Discussion}

High BP is a basic feature of preeclampsia, related to classification. Hadd in 1999 recorded a $95 \mathrm{mmHg}$ diastolic BP related to a significant increase in perinatal mortality, similar to Murphy's diastolic BP $85 \mathrm{mmHg}$ combined with proteinuria also increased perinatal mortality. The basis of diastolic BP selection to predict the severity of preeclampsia is due to diastolic BP showing peripheral resistance and systolic BP reflecting cardiac output. In preeclampsia to date, there has been an imbalance between the contraction and vasodilation, including a decrease in prostacyclin (vasodilation) and an increase in thromboxan A2 (vasoconstriction). As a result, the blood vessels are constricted, causing high $\mathrm{BP}$ and causing platelet adhesion in the vessels $[2,6,8,9]$.

In order to diagnose high BP in preeclampsia, many authors believe that it is necessary to measure BP at least 2 hours apart 4 hours after women take a rest. However, the diagnostic criteria in our study were chosen according to Sibai and Uzan, the 4-hour interval could be reduced if the diastolic BP from the first measurement was $110 \mathrm{mmHg}$ or more [7]. Nicardipine prevents calcium ions into cardiac muscle cells and smooth muscle (more vascular smooth muscle on myocardium), causing vasodilation, reducing peripheral resistance and resulting in lowering blood pressure. The drug does not affect the electrical activity of the 
heart muscle. The effect of increasing heart rate is normal when there is vasodilatation and hypotension (average heart rate increases 5-10 beats per minute when compared to placebo). Recorded increase in cardiac output due to reduced afterload and increased heart rate, increased ejection fraction $[1,2,5]$.

In order to control BP in cases of severe preeclampsia or eclampsia (when diastolic BP is $\geq 110 \mathrm{mmHg}$ ), many authors still choose to use hydralazine slowly, repeat if the BP is still unstable $[2,9]$. Currently due to scarce supplies, hydralazin is not available. An intravenous labetalol is also a common option but the actual supply is difficult [3]. The tendency to use Nicardipine in cases of dangerous high blood pressure becomes widespread. Using intravenous nicardipine will help lower blood pressure and maintain BP stability with a safety level for pregnant women and not unduly reduce the ability to placate each other-fetus $[1,3,5]$. The BP starts to decline after 30-45 minutes, the intravenous infusion reaches the BP target of $225 / 323$ cases $(69.7 \%)$ and this rate increases proportionally over time, the highlight is the hypotensive happening from words and control and this is the main purpose of the study. The starting dose in the study was only about $33 \%$ (2.5mg versus $7.5 \mathrm{mg} /$ hour) compared to the dose that began to be noted from studies in the literature. After 45-60 minutes, only $31.3 \%$ need the same dose as the medical record $[1,3,5]$.

\section{Side effects (Table 3)}

most noted is vasodilatation that increases maternal vascularity with 30 maternal vascular cases more than 120 times per minute accounting for $9.3 \%$, however fast pulse does not exceed 130 times per minute and There were no cases of hypotension (blood pressure below $90 / 60 \mathrm{mmHg}$ ) in pregnant women. Fetal heart faster than 160 beats/minute and less than 180 beats/minute with 26 cases, accounting for $8.0 \%$, these cases occur on rapid maternal cases and none of the cases show periodic circulatory failure Pregnancy by monitoring CTG (Cardiotocography based on the standards of the American Society of Obstetrics and Gynecology, 2009). Epidemic phlebitis has 14 out of 323 cases (4.3\%), this phenomenon occurs on average after 24 hours of nicardipine infusion, the area of the red infusion site. Management changes the transmission position after 12 hours. There is one case of antibiotic treatment. Chest tightness has $3 / 323$ cases $(0.3 \%)$, these cases do not record changes in ECG (measured immediately after chest tightness) and clinically not recorded abnormally. Other adverse effects such as blushing, tremor, dyspnea, pulmonary edema, coal allergy ... have not been recorded in this group. The limitation of the study is that because it is a high-risk disease for pregnant women and fetuses, we can only select the non-control study model despite knowing that the results obtained will be greatly reduced.

\section{Conclusion}

Through research, we recorded the efficacy and safety of intravenous Nicardipine for antihypertensive treatment in severe pre-eclampsia. The effect of antihypertensive with fast calculation time, high ability to maintain high blood pressure limits complications due to high blood pressure for pregnant women and fetuses, thereby helping clinicians have more time to evaluate. more accurately the level of pre-eclampsia as well as having more time to choose the appropriate method of termination of pregnancy if indicated.

\section{References}

1. Aya AG, Mangin R, Hoffet M, Eledjam JJ (1999) Intravenous nicardipine for severe hypertension in pre-eclampsia--effects of an acute treatment on mother and foetus. Intensive Care Med 25(11): 1277-1281.

2. Beckmann's Obstetrics and Gynecology In: ( $6^{\text {th }}$ edn), chapter 16 , Hypertension in Pregnancy, p. 175-179.

3. Elatrous S, Nouira S, Ouanes Besbes L, Marghli S, Boussarssar M, et al. (2002) Short-term treatment of severe hypertension of pregnancy: prospective comparison of nicardipine and labetalol. Intensive Care Med 28(9): 1281-1286.

4. Liu CM, Cheng PJ, Chang SD (2008) Maternal complications and perinatal outcomes associated with gestational hypertension and severe preeclampsia in Taiwanese women. J Formo Med Association 107(2): 129-138.

5. Nij Bijvank SW, Duvekot JJ (2010) Nicardipine for the treatment of severe hypertension in pregnancy: a review of the literature. Obstet Gynecol Surv 65(5): 341-347.

6. (1990) National High Blood Pressure Education Program Working Group Report on High Blood Pressure in Pregnancy. Am J Obstet Gynecol 163(5 pt 1): 1691-1712.

7. Sibai B (1992) Hypertension in pregnancy. Obstetrics and gynecology clinics of North America 19: 615-6332.

8. (1988) Geographic variation in the incidence of hypertension in pregnancy. World Health Organization International Collaborative Study of Hypertensive Disorders in Pregnancy. Am J Obstet Gynecol 158: 80-83.

9. Lindheimer MD (1993) Hypertensive Disorders in Pregnancy. William Obstetrics textbook, Chapter 36, pp. 763-817. 
(C) (i) This work is licensed under Creative

BY DOI: 10.19080/JGWH.2019.15.555906
Your next submission with Juniper Publishers will reach you the below assets

- Quality Editorial service

- Swift Peer Review

- Reprints availability

- E-prints Service

- Manuscript Podcast for convenient understanding

- Global attainment for your research

- Manuscript accessibility in different formats

( Pdf, E-pub, Full Text, Audio)

- Unceasing customer service

Track the below URL for one-step submission https://juniperpublishers.com/online-submission.php 